\title{
miR-21 inhibition of LATS1 promotes proliferation and metastasis of renal cancer cells and tumor stem cell phenotype
}

\author{
FENG AN ${ }^{1}$, YIDONG LIU ${ }^{2}$ and YAN HU ${ }^{2}$ \\ ${ }^{1}$ Department of Urinary Surgery, Affiliated Hospital of Hebei University, Baoding, Hebei 071000; \\ ${ }^{2}$ Department of Urinary Surgery, Taian City Central Hospital, Taian, Shandong 271000, P.R. China
}

Received September 28, 2016; Accepted March 10, 2017

DOI: $10.3892 / 01.2017 .6746$

\begin{abstract}
MicroRNA (miR)-21 has many regulatory functions in the cell, including activities in cancer cells and cancer stem cells. Large tumor suppressor gene 1 (LATS1) is a target of miR-21 that could mediate several of these phenotypes. This study explored the effect of miR-21 silencing in renal cancer cell function and LATS1 expression. Silencing of miR-21 in Caki-2 cells reached an efficiency of $55-60 \%$. This was sufficient to detect decrease in Caki-2 cell proliferation and migration invasion capacity. miR-21 silencing increased LATS1 expression at both mRNA and protein levels. The number of tumor spheres formed by cells expressing si-miR-21 was significantly reduced and the expression of tumor stem cell markers Nanog and CT3/4 were significantly downregulated. miR-21 seems to regulate LATS1 expression in renal cancer Caki-2 cells, resulting in reduced proliferation, invasion, and cancer stem cell phenotype. miR-21 may promote malignant phenotype of tumor cells through LATS1 silencing, which can be regarded as a new target candidate gene for renal cancer treatment.
\end{abstract}

\section{Introduction}

Renal cell carcinoma (RCC) originates from the malignant tumor of the epithelium system of urinary tubule of renal parenchyma. RCC has become the malignant tumor with the highest mortality in the urinary system, accounting for 2-3\% of adult malignant tumors $(1,2)$. The incidence of RCC shows an upward trend each year, ranking 10 in the incidence rate of male malignant tumors in China in 2008. The causes and pathogenesis of RCC are still unclear.

Correspondence to: Dr Yan $\mathrm{Hu}$, Department of Urinary Surgery, Taian City Central Hospital, 29 Longtan Road, Taian, Shandong 271000, P.R. China

E-mail: huyan20160520@163.com

Key words: miR-21, large tumor suppressor gene 1, renal cancer, tumor stem cell
MicroRNAs (miRs) are non-coding, small RNAs 19-25 nucleotides long. The function of miRs is mainly to degrade mRNA of target genes through binding to the $3^{\prime}$ untranslated region (3), thereby regulating the expression and function of downstream genes. miRs participate in the regulation of development, cell apoptosis, proliferation and differentiation and other fundamental cell biology activities $(4,5)$. In recent years it was discovered that many miRs play an important role in the development of tumors such as proto-oncogenes or tumor suppressor genes. Among them miR-21 is the most prominent. Experimental results suggest that in most of the tumors, such as malignant glioma, breast cancer, bile duct cancer, pancreatic cancer, lung cancer, rectal cancer, bladder cancer, kidney cancer, and esophageal cancer, the expression of miR-21 is significantly increased (6-14) indicating that miR-21 plays an important role in the development of tumors.

The Hippo signaling pathway is an evolutionarily conserved regulator of cell growth inhibition. In mammals, when the receptor receives the growth inhibitory signals, it will phosphorylate downstream effectors YAP after the phosphorylation cascade reaction of a series of kinase complexes. Phosphorylated YAP interacts with cytoskeletal proteins, is retained in the cytoplasm and cannot enter the nucleus to exercise transcriptional activation, thus regulating organ size and volume. In addition, recent studies have confirmed the Hippo signaling pathway is also involved in the regulation of cancer, tissue regeneration, and the function of stem cells. Large tumor suppressor gene 1 (LATS1) binds and phosphorylates YAP1 in vitro and in vivo, affecting its transcription regulation $(15,16)$. Studies show that low expression of LATS1 can lead to the occurrence of astrocytoma, breast cancer, head and neck squamous cell carcinoma, colorectal cancer, cervical cancer, gastric cancer, skin cancer, metastatic prostate cancer, and RCC (17-25). Some studies propose that miR-21 can resist radiation therapy by inhibiting the expression of LATS1 in ovarian cancer cells (26). LATS1 mRNA may be a direct target of miR-21 and the relationship between miR-21 and LATS1 in RCC has not been reported yet. This study used small interfering RNA (siRNA) to silence miR-21 expression in RCC Caki-2 cells. We also observed the role of miR-21 in renal carcinoma cell proliferation and invasion, and tumor stem cell phenotype to help understand miR-21 function and its targets. 


\section{Materials and methods}

Cell line and main reagents. Human renal carcinoma Caki-2 cells were from American Type Culture Collection (ATCC; Manassas, VA, USA), Dulbecco's modified Eagle's medium (DMEM) culture and fetal bovine serum from Gibco Life Technologies (Carlsbad, CA, USA), methyl thiazolyl tetrazolium (MTT) kit from Sigma (St. Louis, MO, USA), miR isolation extraction and separation kit, RPMI-1640, Lipofectamine $^{\circledR} 2000$ and TRIzol from Invitrogen Life Technologies (Carlsbad, CA, USA). The quantitative (qPCR) (qPCR) Mix kits were from Takara Bio, Inc. (Otsu, Japan) and mouse monoclonal LATS1 antibody (dilution, 1:500; cat. no. sc-398560), mouse monoclonal Nanog antibody (dilution, 1:500; cat. no. sc-293121), mouse monoclonal OCT3/4 (dilution, 1:500; cat. no. sc-5279), and mouse monoclonal GAPDH antibody (dilution, 1:500; cat. no. sc-293335) were from Santa Cruz Biotechnology, Inc. (Santa Cruz, CA, USA). Primers were designed and synthesized by Shanghai Jima Pharmaceutical Technology Co., Ltd. (Shanghai, China). si-miR-21 and si-negative control were synthesized by Shanghai Jima Pharmaceutical Technology. si-miR-21 forward, 5'-GATCCAUCUTCGAAGUGACTT-3' and reverse, 5'-UGCUCUTUGACGUAUGGAGTT-3'; si-negative control forward, 5'-UUCACCGUACGUCUCACCUGT-3' and reverse, 5'-ACUGGAACCUCUCGCGGAATT-3'; LATS1 forward, 5'-AAATGCCCACATCCGGGAAA-3' and reverse, 5'-ACCT GGCTCTCCCCTTAACA-3'.

si-miR-21 and si-negative control transfection of Caki-2 cells. The cells in the logarithmic growth phase were divided into three groups based on treatment: miR-21, si-miR-21, and si-negative control. When the cell fusion reached $80-90 \%$, transfection was conducted with Lipofectamine ${ }^{\circledR} 2000$ according to instructions. At $48 \mathrm{~h}$ after transfection, $\mathrm{miR}$ was extracted following the manufacturer's instructions. We used light photometer to detect RNA absorbance and calculate RNA concentration and purity. The samples with a rate from 1.8 to 2.1 were selected for further experiments. qPCR was used to conduct comparative analysis of miR-21 mRNA in Caki-2 in the three groups after transfection.

$q P C R$. Total RNA was extracted from the three groups and purified according to the TRIzol kit instructions; $1 \mu \mathrm{g}$ RNA template was converted into cDNA by reverse transcription according to reverse transcription kit. The reaction system was $10 \mu \mathrm{l}$, at $37^{\circ} \mathrm{C}$ for $15 \mathrm{~min}$ and heated at $85^{\circ} \mathrm{C}$ for $30 \mathrm{sec}$. The amplification condition was: $95^{\circ} \mathrm{C}$ for $5 \mathrm{~min}$, then $95^{\circ} \mathrm{C}$ for $30 \mathrm{sec}, 58^{\circ} \mathrm{C}$ for $30 \mathrm{sec}, 72^{\circ} \mathrm{C}$ for $30 \mathrm{sec}$, a total of 30 cycles, and finally $72^{\circ} \mathrm{C}$ for $5 \mathrm{~min}$. Analysis of dissolution curve was conducted after the reaction.

Western blotting. Total protein from cells of the three groups was extracted by RIPA lysis solution plus $1 \%$ PMSF, and the protein concentration was detected by BCA (all from Biosharp, Hefei, China). A 1/4 volume of the protein sample buffer was added, denatured at $100^{\circ} \mathrm{C}$ for $10 \mathrm{~min}$. SDS-polyacrylamide separating gel (Keygen, Nanjing, China) and stacking gel were prepared, Tris glycine electrophoretic buffer solution and equal amount of denatured protein of $\sim 50 \mu \mathrm{g}$ per well were added,

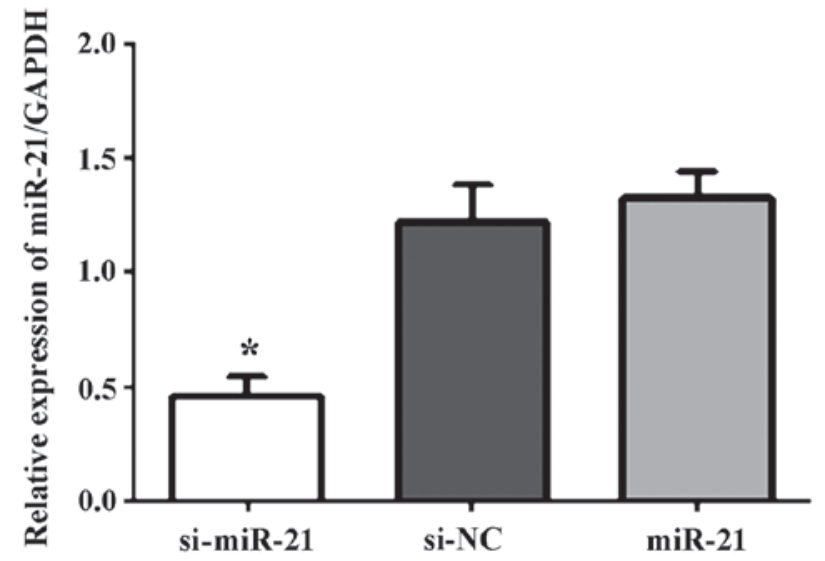

Figure 1. miR-21 mRNA expression after transfection detected by qRT-PCR. ${ }^{*} \mathrm{P}<0.05$.

proteins were transferred to PVDF membrane after electrophoresis and blocked in 3\% BSA for $2 \mathrm{~h}$. Primary antibodies (anti-LATS1 1:1,000; anti-GAPDH 1:1,000) were added at $4^{\circ} \mathrm{C}$ overnight, TBST membrane was washed 3 times $/ 10 \mathrm{~min}$, then horseradish peroxidase-labeled secondary antibodies $(1: 5,000)$ were added at $37^{\circ} \mathrm{C}$ for $2 \mathrm{~h}$, TBST membrane was washed 3 times/10 min, ECL development, and development in vilber lourmat in the dark.

Proliferation assay by MTT. Cells from each group were inoculated in 96-well culture plate at a density of $2 \times 10^{3}$ cells/well. Three multiple pores were set and $2 \mathrm{ml}$ of $5 \mathrm{mg} / \mathrm{ml} \mathrm{MTT} \mathrm{was}$ added to each pore after 24, 48, 72, 96 and $120 \mathrm{~h}$. They were incubated for $4 \mathrm{~h}$, then the supernatant was discarded, $150 \mu \mathrm{l}$ of DMSO was added, mixed, dissolved and crystallized. The light density value [D (490)] in each pore was determined at $490 \mathrm{~nm}$ wavelength, and cell proliferation inhibitory rate (IR): was calculated IR = [1-experimental group D (490)/the control group D (490)] x 100 .

Invasion ability of Caki-2 cells by Transwell. Experiments were conducted according to the BioCoat Matrigel invasion chamber kit instructions. Eight different visual fields (magnification, x100) were counted under the microscope, repeating 3 times, and the percentage of the invasion cells was calculated.

Tumor sphere formation. Serum-free medium (SFM) was prepared with Ham's DMEM-F12 (1:1), B27 (1:50), EGF (20 $\mathrm{mg} / \mathrm{ml})$, and bFGF (20 $\mathrm{ng} / \mathrm{ml})$. The cells of the three groups were inoculated in DMEM with $10 \%$ fetal bovine serum until the cells were in the logarithmic growth phase, and they were washed with PBS, digested with $0.25 \%$ trypsin, and washed in PBS twice after digestion. Then the cells were placed in the low adhesion culture in suspension for $48 \mathrm{~h}$ and changes in cell morphology were observed under an inverted microscope. The formation of tumor spheres was observed and the numbers of tumor spheres were counted after 14 days.

Statistical analysis. SPSS 19.0 software (SPSS, Inc., Chicago, IL, USA) was used for plotting and statistical analysis, measurement data are expressed by mean \pm standard deviation, comparison of rate was tested by $\chi^{2}$, GraphPad Prism 5.0 
A

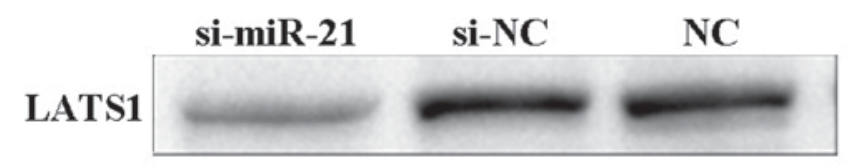

GAPDH

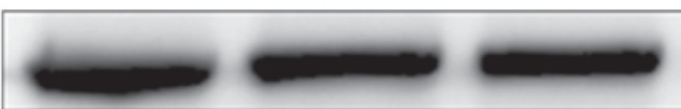

B

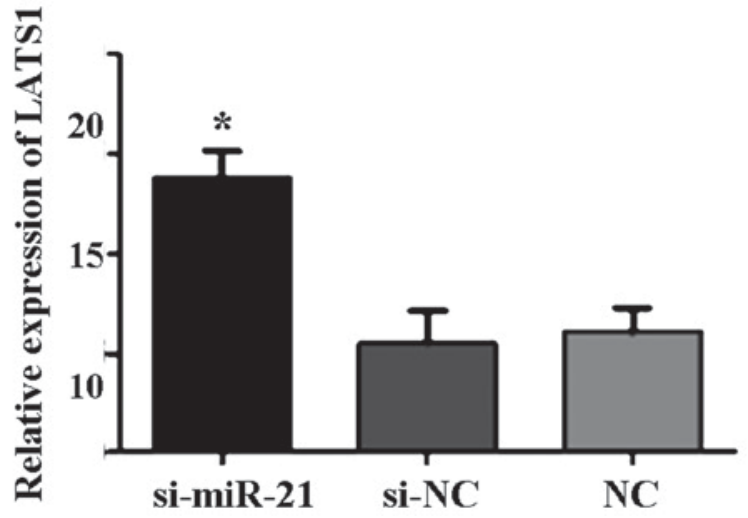

Figure 2. LAST1 expression by western blotting and qRT-PCR. (A) LAST1 expression after transfection detected by western blotting. (B) LAST1 expression at mRNA level after transfection detected by qRT-PCR. ${ }^{*}<0.05$.

(GraphPad Software, Inc., La Jolla, CA, USA) was used to carry out one-way ANOVA analysis and plotting for qPCR results, $\mathrm{P}<0.05$ was considered to indicate a statistically significant difference.

\section{Results}

Efficiency of siRNA transfection by qPCR. According to qPCR, transfection of Caki-2 cells with si-miR-21 resulted in significant reduction of miR-21 compared to transfection with si-negative control $(\mathrm{F}=71.90, \mathrm{P}<0.05)$. The silencing efficiency was $55-60 \%$ (Fig. 1).

LATS1 expression after transfection of miR-21 knockdown. Western blot analysis showed that the expression level of LATS1 protein was significantly higher in cells transfected with si-miR-21 compared to control cells and si-negative cells (Fig. 2A). qPCR showed that LATS1 mRNA expression was significantly higher in cells transfected with si-miR-21 compared to control and si-negative cells $(\mathrm{F}=108.5, \mathrm{P}<0.05$; Fig. 2B).

Proliferation of Caki-2 cells after miR-21 silencing. Following cell transfection, we collecting cell number data at 1,24 , 48, 72, 96 and $120 \mathrm{~h}$. We found no significant differences at 24 and $48 \mathrm{~h}$, but si-miR-21 showed lower proliferation after $72 \mathrm{~h}$ (Fig. 3). The proliferation rate at $72 \mathrm{~h}$ was: $40.5 \pm 11.6 \%$ for si-miR-21, $57.4 \pm 5.9 \%$ for si-negative control, and $58.3 \pm 4.3 \%$ for non-transfected control $(\mathrm{t}=2.375, \mathrm{P}<0.05)$. Cell proliferation at 96 h was: $43.7 \pm 12.5 \%$ for si-miR-21, $75.6 \pm 7.5 \%$ for si-negative control, and $78.3 \pm 6.9 \%$ for non-transfected control $(\mathrm{t}=4.587$, $\mathrm{P}<0.01)$. Cell proliferation at $120 \mathrm{~h}$ was: $48.9 \pm 12.3 \%$ for si-miR-21, 81.9 $\pm 4.6 \%$ for si-negative control, and $85.2 \pm 3.8 \%$ for non-transfected control $(\mathrm{t}=5.698, \mathrm{P}<0.01)$. Thus, si-miR-21 intervention inhibited the proliferation capacity of Caki-2 cells.

Caki-2 cell invasion after si-miR-21 transfection. The invasion ability of Caki-2 cells transfected with si-miR-21 significantly decreased compared to the si-negative control cells and the non-transfected cells ( $\mathrm{F}=135.1, \mathrm{P}<0.01$; Fig. 4). Thus, miR-21 knockdown reduces the invasivity of Caki-2 cells.

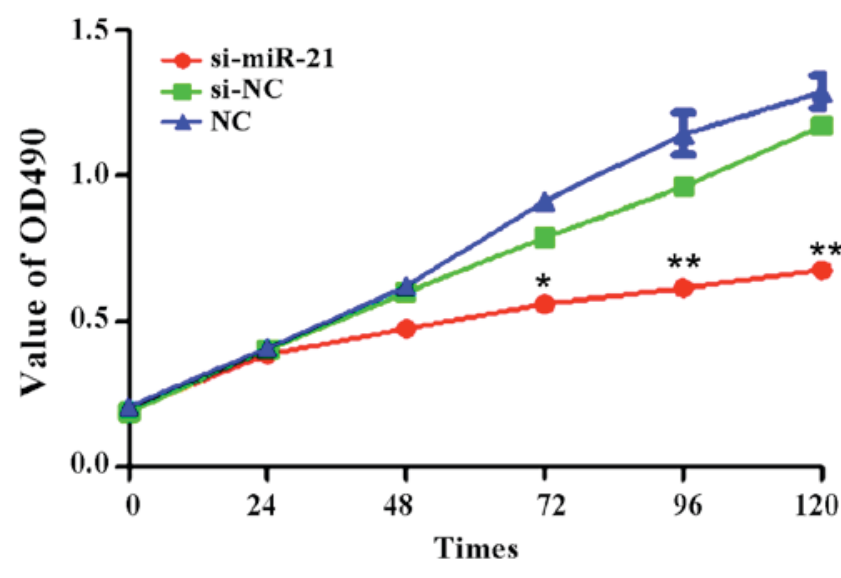

Figure 3. Caki-2 proliferation after transfection detected by MTT. ${ }^{*} \mathrm{P}<0.05$, ${ }^{* *} \mathrm{P}<0.01$.

Tumor sphere formation. Compared to the si-negative control cells and the non-transfected cells, the number of Caki-2 cells forming tumor spheres significantly decreased in cells transfected with si-miR-21 ( $\mathrm{F}=46.17, \mathrm{P}<0.05$; Fig. 4).

Phenotype of cancer stem cells. Last, we examined the ability of miR-21 to regulate the stem cell characteristics of Caki-2 cells. For this, we determined the expression of the stem cell markers, OCT3/4 and Nanog. Caki-2 cells transfected with si-miR-21 showed significantly decreased levels of OCT3/4 and Nanog compared to the si-negative control cells and the non-transfected cells (Fig. 5). These results suggest a role for miR-21 in the regulation of the stem cell state and the transformation into tumorous state.

\section{Discussion}

miRs are endogenous regulatory molecules that play roles as oncogenes or tumor suppressor genes in the development of tumors. As one of the most studied miRs in recent years, miR-21 is highly expressed in gastric cancer, breast cancer, colon cancer, and other tumors, and can be used as a marker to determine the prognosis of various tumors. Some studies suggest that miR-21 overexpression downregulate LATS1 
A
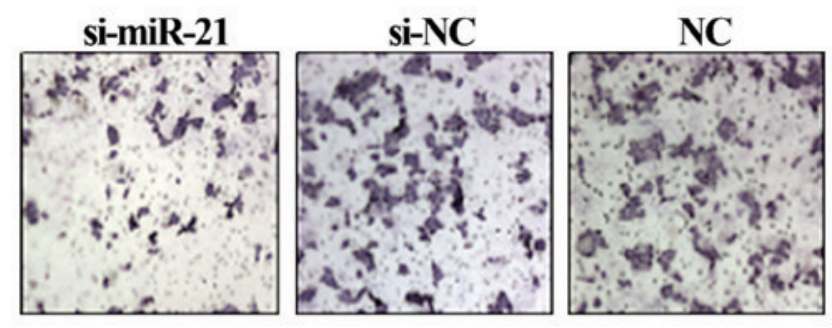

B

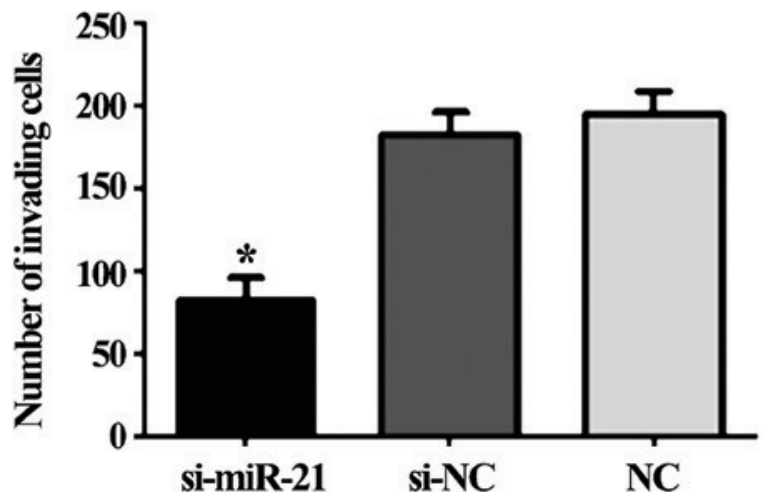

Figure 4. (A and B) Detection of invasion ability after transfection. ${ }^{*} \mathrm{P}<0.05$.

A
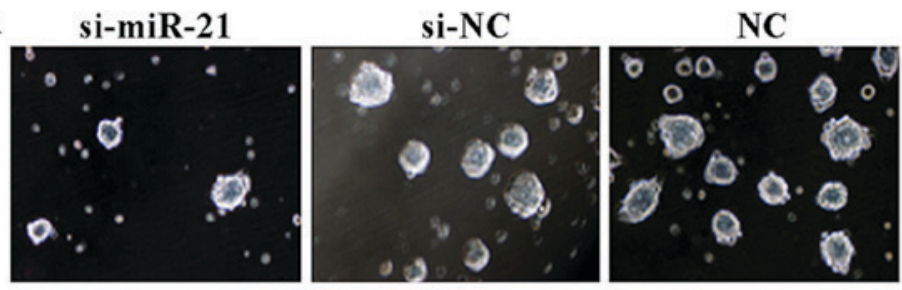

B

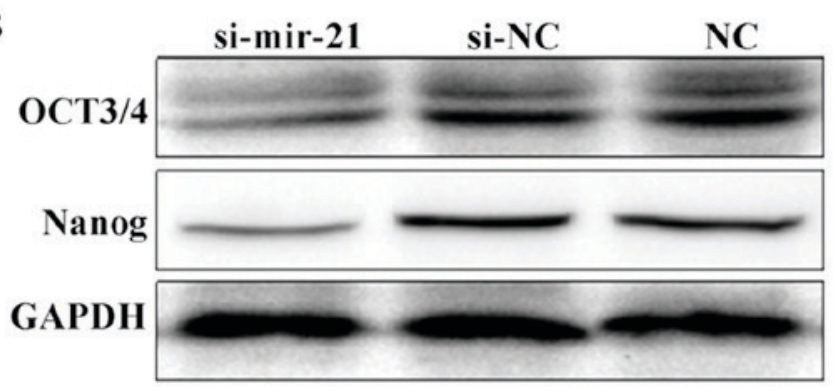

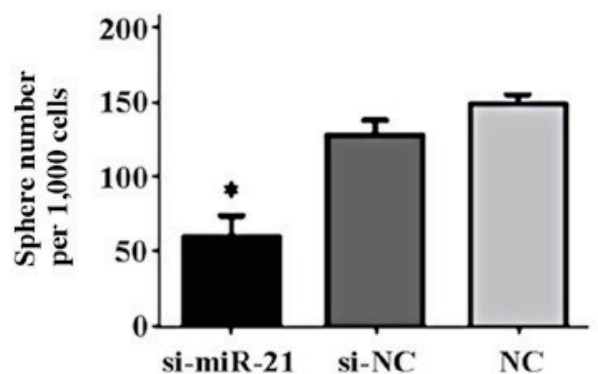

Figure 5. miR-21 regulation of stem cell qualities. (A) Tumor sphere formation. (B) Western blotting detection of OCT3/4 and Nanog. * $<<0.05$.

expression. A large number of studies have found that as one of the key factors in the hippo-Yap signaling pathway, LATS1 expression is reduced in a variety of tumors, which may be related to the high expression of miR-21 (27-29).

Here we showed that silencing miR-21 in Caki-2 cells decreased the proliferation ability after $72 \mathrm{~h}$ and continued to decrease until $120 \mathrm{~h}$. Downregulation of miR-21 also resulted in elevated LATS1 expression, indicating that miR-21 has a regulatory effect on the expression of LATS1. miR-21 is known to regulate cell differentiation, proliferation, development, apoptosis, metabolism and cancerous transformation (30).

Tumor stem cells have self-renewal capacity and can produce heterogeneous tumor cells. They can sustain the vitality of the tumor cell population through self-renewal, unlimited proliferation, movement, and migration ability to promote the transfer of tumor cells. Cancer stem cells can be in a dormant state for a long time and are insensitive to a variety of chemotherapeutic drugs and external physicochemical factors killing tumors, resulting in antitumor drug resistance and reducing the treatment effect. To clarify the mechanism regulating tumor stem cell state is very important for the treatment of tumors. This study found that downregulation of miR-21 inhibited the phenotype of tumor stem cells.

Our study results show that silencing miR-21 expression inhibited the malignant activities of renal carcinoma cells. This inhibition may be induced by downregulation of LATS1 expression and miR-21 may be seen as a marker for diagnosis and prognostic analysis of RCC and LATS1 may become a new target for treatment.

\section{References}

1. Creighton CJ, Morgan M, Gunaratne PH, Wheeler DA, Gibbs RA, Gordon Robertson A, Chu A, Beroukhim R, Cibulskis K, Signoretti S, et al; Cancer Genome Atlas Research Network: Comprehensive molecular characterization of clear cell renal cell carcinoma. Nature 499: 43-49, 2013.

2. Junker K, Ficarra V, Kwon ED, Leibovich BC, Thompson RH and Oosterwijk E: Potential role of genetic markers in the management of kidney cancer. Eur Urol 63: 333-340, 2013.

3. Silahtaroglu A and Stenvang J: MicroRNAs, epigenetics and disease. Essays Biochem 48: 165-185, 2010.

4. Ross SA and Davis CD: MicroRNA, nutrition, and cancer prevention. Adv Nutr 2: 472-485, 2011.

5. Nimmo RA and Slack FJ: An elegant miRror: microRNAs in stem cells, developmental timing and cancer. Chromosoma 118: 405-418, 2009. 
6. Chan JA, Krichevsky AM and Kosik KS: MicroRNA-21 is an antiapoptotic factor in human glioblastoma cells. Cancer Res 65: 6029-6033, 2005.

7. Volinia S, Calin GA, Liu CG, Ambs S, Cimmino A, Petrocca F, Visone R, Iorio M, Roldo C, Ferracin M, et al: A microRNA expression signature of human solid tumors defines cancer gene targets. Proc Natl Acad Sci USA 103: 2257-2261, 2006.

8. Selaru FM, Olaru AV, Kan T, David S, Cheng Y, Mori Y, Yang J, Paun B, Jin Z, Agarwal R, et al: MicroRNA-21 is overexpressed in human cholangiocarcinoma and regulates programmed cell death 4 and tissue inhibitor of metalloproteinase 3. Hepatology 49 : 1595-1601, 2009

9. Dillhoff M, Liu J, Frankel W, Croce C and Bloomston M MicroRNA-21 is overexpressed in pancreatic cancer and a potential predictor of survival. J Gastrointest Surg 12: 2171-2176, 2008.

10. Xie Y, Todd NW, Liu Z, Zhan M, Fang H, Peng H, Alattar M, Deepak J, Stass SA and Jiang F: Altered miRNA expression in sputum for diagnosis of non-small cell lung cancer. Lung Cancer 67: 170-176, 2010

11. Rossi L, Bonmassar E and Faraoni I: Modification of miR gene expression pattern in human colon cancer cells following exposure to 5-fluorouracil in vitro. Pharmacol Res 56: 248-253, 2007.

12. Neely LA, Rieger-Christ KM, Neto BS, Eroshkin A, Garver J, Patel S, Phung NA, McLaughlin S, Libertino JA, Whitney D, et al: A microRNA expression ratio defining the invasive phenotype in bladder tumors. Urol Oncol 28: 39-48, 2010.

13. Lv L, Huang F, Mao H, Li M, Li X, Yang M and Yu X: MicroRNA-21 is overexpressed in renal cell carcinoma. Int J Biol Markers 28: 201-207, 2013.

14. Feber A, Xi L, Luketich JD, Pennathur A, Landreneau RJ, Wu M, Swanson SJ, Godfrey TE and Litle VR: MicroRNA expression profiles of esophageal cancer. J Thorac Cardiovasc Surg 135: 255-260, discussion 260, 2008

15. Mo JS, Park HW and Guan KL: The Hippo signaling pathway in stem cell biology and cancer. EMBO Rep 15: 642-656, 2014.

16. Harvey K and Tapon N: The Salvador-Warts-Hippo pathway - an emerging tumour-suppressor network. Nat Rev Cancer 7 : 182-191, 2007

17. Jiang Z, Li X, Hu J, Zhou W, Jiang Y, Li G and Lu D: Promoter hypermethylation-mediated down-regulation of LATS1 and LATS2 in human astrocytoma. Neurosci Res 56: 450-458, 2006.

18. Takahashi Y, Miyoshi Y, Takahata C, Irahara N, Taguchi T, Tamaki Y and Noguchi S: Down-regulation of LATS1 and LATS2 mRNA expression by promoter hypermethylation and its association with biologically aggressive phenotype in human breast cancers. Clin Cancer Res 11: 1380-1385, 2005.
19. Steinmann K, Sandner A, Schagdarsurengin U and Dammann RH: Frequent promoter hypermethylation of tumor-related genes in head and neck squamous cell carcinoma. Oncol Rep 22: 1519-1526, 2009.

20. Wierzbicki PM, Adrych K, Kartanowicz D, Stanislawowski M, Kowalczyk A, Godlewski J, Skwierz-Bogdanska I, Celinski K, Gach T, Kulig J, et al: Underexpression of LATS1 TSG in colorectal cancer is associated with promoter hypermethylation. World J Gastroenterol 19: 4363-4373, 2013.

21. Visser S and Yang X: Identification of LATS transcriptional targets in HeLa cells using whole human genome oligonucleotide microarray. Gene 449: 22-29, 2010

22. Zhou GX, Li XY, Zhang Q, Zhao K, Zhang CP, Xue CH, Yang K and Tian ZB: Effects of the hippo signaling pathway in human gastric cancer. Asian Pac J Cancer Prev 14: 5199-5205, 2013.

23. Nishio M, Hamada K, Kawahara K, Sasaki M, Noguchi F, Chiba S, Mizuno K, Suzuki SO, Dong Y, Tokuda M, et al: Cancer susceptibility and embryonic lethality in Mobla/1b double-mutant mice. J Clin Invest 122: 4505-4518, 2012.

24. Zhao B, Li L, Wang L, Wang CY, Yu J and Guan KL: Cell detachment activates the Hippo pathway via cytoskeleton reorganization to induce anoikis. Genes Dev 26: 54-68, 2012.

25. Chen KH, He J, Wang DL, Cao JJ, Li MC, Zhao XM, Sheng X, Li WB and Liu WJ: Effects of LATS1 gene methylation on biological function in human renal cell carcinoma and Hippo-YAP signaling pathway. J Third Mil Med Univ 36: 1249-1254, 2014.

26. Liu S, Song L, Zhang L, Zeng S and Gao F: miR-21 modulates resistance of HR-HPV positive cervical cancer cells to radiation through targeting LATS1. Biochem Biophys Res Commun 459: 679-685, 2015

27. Teteloshvili N, Smigielska-Czepiel K, Yuan Y, Seitz A, de Jong D, Rutgers B, Jellema P, van der Lei RJ, Slezak-Prochazka I, Brouwer E, et al: Argonaute 2 immunoprecipitation revealed large tumor suppressor kinase 1 as a novel proapoptotic target of miR-21 in T cells. FEBS J 284: 555-567, 2017.

28. Liu S, Song L, Zhang L, Zeng S and Gao F: miR-21 modulates resistance of HR-HPV positive cervical cancer cells to radiation through targeting LATS1. Biochem Biophys Res Commun 459: 679-685, 2015 .

29. Xia H, Qi H, Li Y, Pei J, Barton J, Blackstad M, Xu T and Tao W: LATS1 tumor suppressor regulates G2/M transition and apoptosis. Oncogene 21: 1233-1241, 2002.

30. Chen J and Wang X: MicroRNA-21 in breast cancer: Diagnostic and prognostic potential. Clin Transl Oncol 16: 225-233, 2014. 